\title{
CHEMSEX AND HARM REDUCTION: AN UNDER-EXPLORED REALITY
}

B.B. Rahe ${ }^{1}$, T.M. Fidalgo².

\section{Objectives:}

The objective of this study is to review the literature about the importance of Harm Reduction $(\mathrm{HR})$ in individuals who use Chemsex.

\section{Background:}

Chemsex is a term commonly used by men who have sex with men (MSM) to describe the use of psychoative substances in a sexual context. In Brazil as well as in the rest of the world, alcohol, cocaine, cannabis and poppers were the most used substances during sex, but recently there has been a significant increase in the use of substances, such as methamphetamine, mephedrone, GHB/GBL, ecstasy and ketamine.(1)
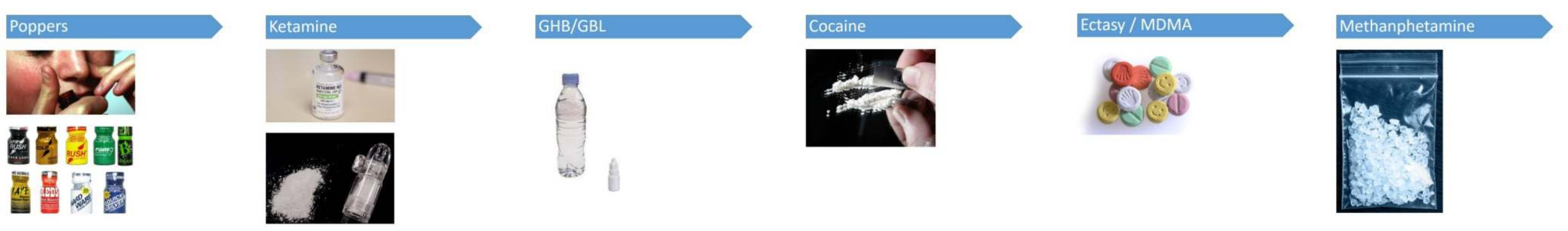

\section{Materials and Methods:}

Our research strategy included the terms ChemSex AND Harm Reduction, in all fields of knowledge, to be as broad as possible. The terms were searched in articles which had the following database: MEDLINE, Web of Science and Cochrane.

\section{Results:}

In this first analysis, 35 articles were found related to the Chemsex and HD, from these ones, 26 were considered in this study, and 9 were not used, because, in most of them, Chemsex was mentioned but with no direct connection with HD. The sexual context of Chemsex use entails several risks, whether the substance direct action (overdose or addiction) and risk situations for STI or behaviors that the person would not usually have. In medical visits, Chemsex is hardly ever mentioned, and health care services are not prepared to answer to the population needs, mainly in relation to HD.

\section{Discussion and Conclusions:}

Chemsex has become increasingly common in homosexual, bisexual and heterosexual men and women (2) although historically linked to MSM (3). Dating apps have been very important for the widespread use of Chemsex, both for the sale of substances and for arranging sexual encounters for substance use. (4) This ease of access and the direct link between substance use and sexual pleasure makes a prohibitionist approach quite controversial. $(5,6)$ The harm reduction approach should be considered for both substance use and risky sexual behavior, especially for sexually transmitted infections. (7) In this way, the harm reduction strategy, appears to be of great importance to health is addressed in a comprehensive manner, taking into account physical, mental and sexual issues.

The understanding of the use of Chemsex among MSM is multifactorial and deserves more studies. But it is possible to notice that HD approach to harmful effects of the substances and risky sexual behavior appears to be a good strategy, since abstinence from substance can be ssen at first as abstinence from sex. $(8,9)$

References: 1.Maxwell S, Shahmanesh M, Gafos M. Chemsex behaviours among men who have sex with men: A systematic review of the literature. Int J Drug Policy [Internet]. 2019 Jan;63:74-89. Available from: http://www.ncbi.nlm.nih.gov/pubmed/30513473 | 2. Lawn W, Aldridge A, Xia R, Winstock AR. Substance-Linked Sex in Heterosexual, Homosexual, and Bisexual Men and Women: An Online, Cross-Sectional "Global Drug Survey" Report. J Sex Med [Internet]. 2019 May [cited 2019 May 7];16(5):721-32. Available from: http://www.ncbi.nlm.nih.gov/pubmed/30952548 | 3. Barrett P, O'Donnell K, Fitzgerald M, Schmidt AJ, Hickson F, Quinlan M, et al. Drug use among men who have sex with men in Ireland: Prevalence and associated factors from a national online survey. Int $J$ Drug Policy [Internet]. 2019 Feb [cited 2019 Jan 9];64:5-12. Available from: https://linkinghub.elsevier.com/retrieve/pii/S0955395918302950 | 4.Denio Lourenco. Sex and drugs: Popular gay dating app allows users to find more than a date [Internet]. Aug. 1, 1:16 PM GMT-3. 2018 [cited 2019 Aug 15]. Available from: https://www.nbcnews.com/feature/nbc-out/sex-drugs-popular-gay-dating-app-allows-users-find-more-n896081 | 5.Milhet M, Shah J, Madesclaire T, Gaissad L. Chemsex experiences: narratives of pleasure. Drugs and Alcohol Today. 2019;19(1):11-22. | 6.O. S, J.I. F, Stevens O, Forrest JI. Thinking upstream: The roles of international health and drug policies in public health responses to chemsex. Sex Health [Internet]. 2018 Apr;15(2):108-15. | 7. Rahe BB, Fidalgo TM, Silveira DX. Poppers and Sexual Behavior: An Intimate Relationship. J Sex Med [Internet]. 2017;14(5):e296. Available from: http://linkinghub.elsevier.com/retrieve/pii/S1743609517308639 | 8.Stardust Z, Kolstee J, Joksic S, Gray J, Hannan S. A community-led, harm-reduction approach to chemsex: case study from Australia's largest gay city. Sex Health [Internet]. 2018 Apr [cited 2019 May 7];15(2):179-81. Available from: http://www.ncbi.nlm.nih.gov/pubmed/29592830 | 9.Bourne A, Reid D, Hickson F, Torres-Rueda S, Steinberg P, Weatherburn P. "Chemsex" and harm reduction need among gay men in South London. Int J Drug Policy [Internet]. 2015 Dec 1 [cited 2019 May 7];26(12):1171-6. Available from: http://www.ncbi.nlm.nih.gov/pubmed/2629 